head of the Linear Accelerator Research Unit at St. Bartholomew's Hospital, for his help and co-operation.

J. S. KIRBY-SMITH

G. W. DoLPHIN

Physics Department,

St. Bartholomew's Hospital

Medical College,

London.

May 27.

${ }^{1}$ Lea, D. E., "Actions of Radiations on Living Cells", 2nd edit., 225 (Cambridge Univ. Press).

${ }^{2}$ Boag, J. W., Dolphin, G. W.. and Rotblat, J. "Radiation Research" (in the press).

${ }^{3}$ Wolff, S., and Luippold, H. E., Genetics (in the press).

\section{Competition between Genotypes in Drosophila melanogaster}

Ir has been shown by Birch $^{1}$ that the main competitive effect in Drosophila pseudo-obscura is between larvæ. Lewontin ${ }^{2}$ studied the larval viabilities of various strains of $D$. melanogaster mixed with a whiteeyed stock and found that the viability of a genotype is partially dependent on the genotypes co-existing with it.

In a two-point back-cross linkage experiment, the proportion of competing genotypes is different in each phase. Considering such an experiment for two factors $a$ and $b$ which are somewhat inviable in the recessive state, four genotypes are obtained in the offspring :

$$
A B / a b, A b / a b, a B / a b, a b / a b
$$

In coupling, the most and least viable genotypes, $A B / a b$ and $a b / a b$, predominate in the progeny, and hence under crowded conditions there will be a tendency for elimination of $a b / a b$ flies. In repulsion, $A b / a b$ and $a B / a b$ predominate and the main competition is between these two genotypes. The recombinants $A B / a b$ and $a b / a b$ will not compete with each other to any great extent but will compete mainly with the parentals. Hence the elimination of $a b / a b$ will not be as great as in coupling. Thus in very crowded conditions a difference in the viability relations can be expected between coupling and repulsion.

Using the two sex-linked genes, white $(w)$ and miniature $(m)$, results for coupling and repulsion (Table 1) were collected for two-point backcrosses in D. melanogaster for three levels of competition which can be termed low, medium and high levels. For all levels, flies were mated for $48 \mathrm{hr}$. For the low level one pair was mated in a $\frac{1}{2}$-pint milk-bottle, for the medium level one pair in a small vial, and the high level six pairs in a small vial.

Assuming no competition between larvæ, the ratios $w m:++$ and $w+:+m$ should not vary between coupling and repulsion. A simple contingency $\chi_{1}{ }^{2}$ may be done within each level to test this (Table 2 ).

The only significant result is for the high level where the ratio $w m:++$ varies between coupling and

\begin{tabular}{|c|c|c|c|c|c|c|}
\hline & & $w m$ & $w+$ & $+m$ & ++ & Total \\
\hline Low & $\begin{array}{l}C \\
R\end{array}$ & $\begin{array}{l}478 \\
318\end{array}$ & $\begin{array}{l}236 \\
529\end{array}$ & $\begin{array}{l}211 \\
569\end{array}$ & $\begin{array}{l}483 \\
289\end{array}$ & $\begin{array}{l}1,408 \\
1,705\end{array}$ \\
\hline Medium & $\begin{array}{l}C \\
R\end{array}$ & $\begin{array}{l}409 \\
190\end{array}$ & $\begin{array}{l}205 \\
407\end{array}$ & $\begin{array}{l}236 \\
424\end{array}$ & $\begin{array}{l}407 \\
200\end{array}$ & $\begin{array}{l}1,257 \\
1,221\end{array}$ \\
\hline High & $\begin{array}{l}C \\
R\end{array}$ & $\begin{array}{l}506 \\
580\end{array}$ & $\begin{array}{l}288 \\
976\end{array}$ & $\begin{array}{r}300 \\
1,062\end{array}$ & $\begin{array}{l}659 \\
553\end{array}$ & $\begin{array}{l}1,753 \\
3,171\end{array}$ \\
\hline
\end{tabular}

Table 2. $\chi_{1}{ }^{2}$ TESTS FOR $w m:++$ AND $w+:+m$ WITHIN EACH LEVE OF COMPETITION

\begin{tabular}{|c|c|c|c|c|}
\hline \multirow{2}{*}{ Levels } & \multicolumn{2}{|c|}{$w m:++$} & \multicolumn{2}{|r|}{$w+:+m$} \\
\hline & $\chi_{1}{ }^{2}$ & $P$ & $x_{1}{ }^{2}$ & $P$ \\
\hline $\begin{array}{l}\text { Low } \\
\text { Medium } \\
\text { High }\end{array}$ & $\begin{array}{r}0.71 \\
0.16 \\
13.56\end{array}$ & $\begin{array}{c}0.3<P<0.5 \\
0.5<P<0.7 \\
P<0.001\end{array}$ & $\begin{array}{l}2 \cdot 53 \\
0 \cdot 62 \\
0 \cdot 18\end{array}$ & $\begin{array}{l}0.1<P<0.2 \\
0.3<P<0.5 \\
0.5<P<0.7\end{array}$ \\
\hline
\end{tabular}

repulsion. In coupling, the wm flies are of much poorer viability than the ++ flies, but in repulsion this is not so. The less extreme contrast, $w+$ and $+m$, does not show any variation between coupling and repulsion.

This difference arises as a result of differential competition between larvæ according to the proportions of competing genotypes present. The implication of the viability of a genotype varying according to the competing genotypes has not been stressed, although Haldane ${ }^{3}$ deals with it in an early paper. In natural conditions, where competition is much more severe than in artificial laboratory conditions, such effects must assume some importance. Thus selective advantages and disadvantages of a gene or genotype must be considered in relation to the food available, and the types and proportions of the other genotypes in the population.

Further discussion with additional results will be published elsewhere.

Department of Genetics,

P. A. Parsons

University of Cambridge. May 31 .

${ }^{1}$ Birch, L. C., Evolution, 9, 389 (1955).

2 Lewontin, R. C., Evolution, 9, 27 (1955).

${ }^{3}$ Haldane, J. B. S., Trans. Camb. Phil. Soc., 23, 19 (1924).

\section{Effects of Environment (Radiation, Substrate and Allelic Genes) on the Melezitose Gene in Saccharomyces}

THE melezitose locus $(M Z)$ in Saccharomyces controls the formation of the adaptive enzyme, melezitase, which acts on five substrates : turanose $(T)$, maltose $(M)$, sucrose $(S)$, methyl- $\alpha$-D-glucopyranoside $(G)$, and melezitose $(Z)$, each of which may serve as an inducer of melezitase ${ }^{1-3}$. Seven different variations (alleles) of this gene are known and are designated $T M S G Z, T M S G z, T M S g Z, T M S g z, T M s g z$, Tmsgz and $t m s g z^{3}$. The capital letters indicate the substrates which are capable of inducing melezitase in glucosegrown cultures. Cells in which melezitase has been induced by one of the substrates to which it responds adaptively are able to split the substrates which do not act as inducers in that specific genotype without further adaptation. For example, a glucose-grown culture carrying $T M S g z$ responds to neither methyl$\alpha$-D-glucopyranoside nor melezitose, but splits both these substrates after exposure to turanose, maltose or sucrose.

The first evidence of the $M Z$ series came from hybridization experiments. The various genes produced by hybridization were inferred to have resulted from gene conversion in the hybrid since they were stable in the vegetative condition and arose at meiosis of heterozygotes only.

Five genes of the $M Z$ series were obtained by ultra-violet radiation of $T M S G Z$. The limited kinds which were produced by gene conversion and ultraviolet radiation indicate that alterations of the gene 